\title{
Crop phenology based on MODIS satellite imagery as an indicator of plant available water content
}

\author{
$\underline{\text { Sofanit Araya }^{a} \text {, Bertram Ostendorf }}{ }^{\text {, Gregory Lyle }}{ }^{\text {a }}$, Megan Lewis ${ }^{\text {a }}$ \\ ${ }^{a}$ Spatial Information Group, School of Earth and Environmental Sciences, University of Adelaide \\ Email: SofanitGirma.Araya@adelaide.edu.au
}

\begin{abstract}
Maintaining agricultural productivity into the future is one of the most important goals of our society. The world's vast grain production areas in arid environments have a high sensitivity to climate change, thus demanding accurate future predictions. Management and decision making depends on an understanding of complex spatial and temporal interactions between rainfall, temperature and soils, but detailed soil information is extremely costly and generally unavailable.
\end{abstract}

Crop phenology, the timing of plant growth and developmental stages, is the combined response to environmental factors such as soil, water and temperature. Crop phenology plays an important role in crop growth models and agronomic management. In Mediterranean environments like South Australia, water is the driving factor for crop growth. In these rain-fed farming systems, water availability largely depends on rainfall amount and seasonality and the capacity of the soil to retain rainfall inputs and hence make water available for crops. Plant Available Water Capacity of soil (PAWC) is an important measure of the spatial and temporal variability of crop growth and yield, but there is a paucity of detailed maps at a management relevant spatial resolution and extent.

In this study, different phenological metrics derived from MODIS NDVI imagery were assessed over sites of known PAWC and cropping history. We used the metrics:

- $\quad$ NDVI at the onset of greenness (Onset) and time of Onset (OnsetT)

- $\quad$ NDVI at peak greenness (MaxV) and time of maximum greenness (MaxT)

- The length of the growing season (WidthGS)

- $\quad$ Rate of greenup (GURate)

The green up rate of the curve (GU-rate) showed the most consistent difference between soils of different PAWC. The Rate of Green up is higher for the soil points with relatively low PAWC. Some of the variability in the difference between sites with low and high PAWC can be explained with rainfall amount and seasonality but the relationship is complex.

The results indicate that the crop phenology derived from MODIS satellite imagery is consistently different and may therefore provide useful information about site conditions, which would allow improvements to the spatial detail in soil maps.

Keywords: $\quad$ Digital Soil Mapping (DSM), remote sensing, satellite imagery, spatio-temporal 


\section{INTRODUCTION}

Soil information is very important information for policy making and various environmental practices. Most global and regional environmental models need soil information as one of the input parameters (Asseng et al., 1998, Henderson et al., 2005). Missing this information at the global or local scale leads to uncertainty in the basic sustainability decision makings (FAO et al., 2009).

Field measurements of plant available water capacity (PAWC) are expensive and time consuming (Morgan et al., 2000) and there is the need to estimate PAWC through relatively easily measurable soil properties (Mullins, 1981, Morgan et al., 2000, Jiang et al., 2008). Seasonal variability of the crop growth is theoretically related to PAWC variability but it is difficult to extract this information because of the number of factors that influence dynamics of water availability and crop growth.

Vegetation condition and crop growth timing is strongly influenced by underlying soil conditions. The spatial variability of soil PAWC and its interaction with the rainfall seasonality is considered a major cause of the growth variability (McDonald, 2006, Oliver et al., 2006, Wong et al., 2006a, Wong et al., 2006b). In turn, improved understanding of the growth dynamics may allow inferences about the soil's water condition. Vegetation phenology, the timing and seasonality of the plant growth stages, could be a useful indicator of different environmental factors including soil (Reed et al., 1994, Zhang et al., 2003). In non-irrigated agricultural area, phenological phenomena reflect how plants respond to short term weather events (Reed et al., 1994).

The Normalized Difference Vegetation Index (NDVI) has been used in many vegetation phenologic studies, including global land cover classification (Lloyd, 1990, DeFries et al., 1995), crop classification (Wardlow et al., 2007, Wardlow et al., 2008, Sun et al., 2012), and agricultural productivity estimation (Hill et al., 2003, Kouadio et al., 2012). Moderate Resolution Imaging Spectroscopy (MODIS), mounted on the NASA Earth Observation System's Terra Spacecraft, provides vegetation indices with the resolution of $250 \mathrm{~m}-1 \mathrm{~km}$. The NDVI data from MODIS is one of the most widely used satellite images for time series analysis (Rodrigues et al., 2011). Despite the usefulness of MODIS NDVI for understanding of the plant and environmental conditions, little evidence exists if NDVI dynamics can be used as a spatial indicator for environmental factors that control the plant growth such as soil conditions.

In this paper we assess plant dynamics within two cropping paddocks in different climate zones that have marked differences in PAWC and area sufficiently large to be used with MODIS imagery. We have derived phenological metrics from the time series MODIS NDVI images are used to explore the seasonal variation of vegetation and its interaction with the climatic conditions to examine the response of the soil PAWC to different rainfall amount and seasonality.

\section{MATERIALS AND METHODS}

The study was carried out on two paddocks around Wharminda and Minnipa towns in the upper Eyre Peninsula, South Australia. The sites were selected for their setting with the soil types which may represent wider area coverage of the Eyre Peninsula region (Eyre Peninsula Farming Systems, 2009). Both of these farms have been studied as the focus site of the Eyre Peninsula Agricultural Research Foundation (EPARF)(Eyre Peninsula Agricultural Research Foundation 2011). Average annual and growing season rainfall is $325 \mathrm{~mm}$ and $242 \mathrm{~mm}$, respectively.

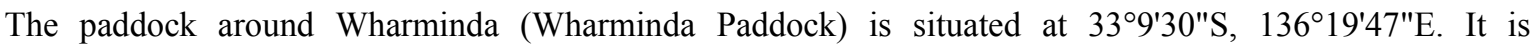
characterized by siliceous sand over sodic clay soil, which approximately represent 455,000 ha area of the Eyre Peninsula(Eyre Peninsula Agricultural Research Foundation 2011). These sands are reported to be a challenge for the farmers due to their uneven wetting nature at the beginning of the growth seasons. This uneven wetting is worse in the deep sand soils. It results in uneven germination at the beginning of the growing season(Eyre Peninsula Farming Systems, 2009). The Minnipa Paddock, N1 at Minnipa Agricultural Center (MAC) is located at $32^{\circ} 48^{\prime} 47^{\prime \prime} \mathrm{S}, 135^{\circ} 9^{\prime} 55^{\prime \prime} \mathrm{E}$.

\section{DATASETS}

MODIS NDVI data (MOD13Q1 16 days composites) was used to estimate phenological indices. The imagery is available from NASA's Earth Observing System (EOS), with ground resolution of 250m. These composites were calculated using Constrained View angle - Maximum Value Composite (CV-MVC) and Maximum Value Composite (MVC) techniques (Solano et al., 2010). The MODIS NDVI data is available since 2000. Thus we will have 273 images (23 images per year except 2000 at which only 20 images available). 
Rainfall data (daily gridded data with $5 \mathrm{~km}$ resolution) was provided by the Australian Government Bureau of Metrology (BOM).

Soil data from APSoil was used in this study. The APSoil was developed for regional use with the Agricultural Production Systems Simulator (APSIM) (The APSIM initiative). The APSoil database is a point based soil characterization. There are around 69 points in the South Australian Agricultural region. The points used in this study are \#394 and \#395 from Wharminda and \#354 and \#353 from Minnipa stations, respectively.

The paddocks were zoned based on yield and Electro Magnetic Survey (EM38) surveys (Eyre Peninsula Agricultural Research Foundation 2011) . The representative soil points were taken from the zones of both paddocks. Table 1 shows the PAWC measurement of these soil points and the soil type at the location. The closest pixels to these soil points were chosen and the NDVI time series data were extracted for those pixels. The chosen pixels are within the representing zones and are the closest possible pixels for the soil points. Moreover, the pair soil points are within the same paddock, which means that the compared MODIS time series are under the same management with constant seeding and fertilser rates.

Table 1. Soil points at the study sites

\begin{tabular}{|c|c|c|}
\hline \multicolumn{3}{|c|}{ Paddock at Wharminda } \\
\hline APSOil ID & PAWC & Soil type \\
\hline $\begin{array}{l}394 \\
395\end{array}$ & $\begin{array}{l}166 \mathrm{~mm} \\
95 \mathrm{~mm}\end{array}$ & $\begin{array}{l}\text { Shallow sand over clay } \\
\text { Loam over rock }\end{array}$ \\
\hline \multicolumn{3}{|c|}{ Paddock at Minnipa } \\
\hline APSOil ID & PAWC & Soil type \\
\hline $\begin{array}{l}353 \\
354\end{array}$ & $\begin{array}{l}57 \mathrm{~mm} \\
209 \mathrm{~mm}\end{array}$ & $\begin{array}{l}\text { Red Sandy Clay Loam } \\
\text { Red light Sandy Clay Loam }\end{array}$ \\
\hline
\end{tabular}

\subsection{Phenological metrics}

We evaluated five different phenological metrics that may be used as indicators for biophysical conditions (Figure1): Onset of greenness, time of Onset of greenness, Maximum greenness, time of maximum greenness, offset of greenness, and time of offset of greenness.

In this study, the onset of greenness was defined as the point where the highest slope observed between two consecutive NDVI values, on the period of March - June. The maximum greenness is the highest NDVI value and loosely correlated with the phenologic period of Anthesis. The offset of greenness (Offset) and time of offset (OffsetT) are defined as a point at which the crop loses its greenness and gets ready for harvest. This point is defined as the point where lowest slope observed in the time series curve. This phenologic event loosely corresponds to the Maturity phenologic stage. Similarly, the time of offset is defined as the time when the offset of greenness is recorded. The length of the growing season (LengthGS) is defined as the duration of the period between the Onset of greenness and offset of greenness. The rate of greenup (GURate) is defined as the rate at which the NDVI increased from onset to the maximum greenness. It is calculated as the slop of the straight line between the onset of greenness and the maximum NDVI i.e (Maximum NDVI-Onset of greenness)/ (time of maximum

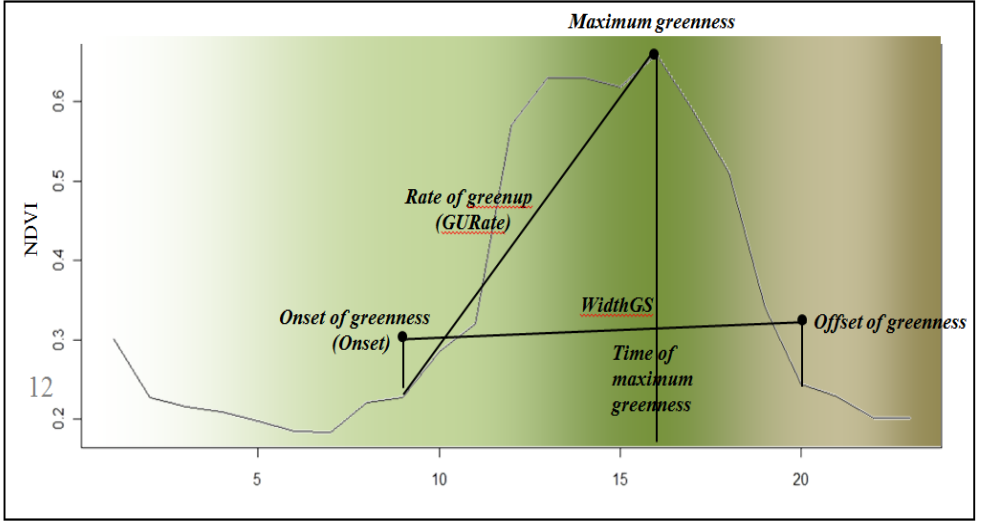

Figure 1. Phenological metrics used in this study greenness-time of onset).

\section{RESULTS}

A comparison of time series of NDVI of twelve years $(2000-2011)$ at the soil sites in both stations shows noticeable differences (Figure 2). 
In Wharminda paddock, the MaxV for all the years from Pixel 395 (low PAWC) was higher than that of Pixel 394. Maximum NDVI was also observed to appear 15 - 30 days earlier than that of 394. Similarly the OnsetT also showed marked differences. In most of the years both Onset of greenness and maximum NDVI were earlier at low PAWC. However the difference is not consistent in all the years.

Similarly, in Minnipa paddock, the region with low PAWC (Pixel 353) was characterized by a higher maximum in most of the years. Onset of greenness and maximum NDVI was also observed to be earlier at low PAWC.

The Rate of Greenness (GURate) depends on the onset of greenness and the timing and magnitude of the maximum NDVI. The soil points with relatively lower PAWC, Pixel 395 (Wharminda Paddock) and Pixel 353 (Minnipa paddock), have a higher GURate compared with their corresponding points. However, GURate differed markedly between years, possibly related to rainfall amount and seasonality.

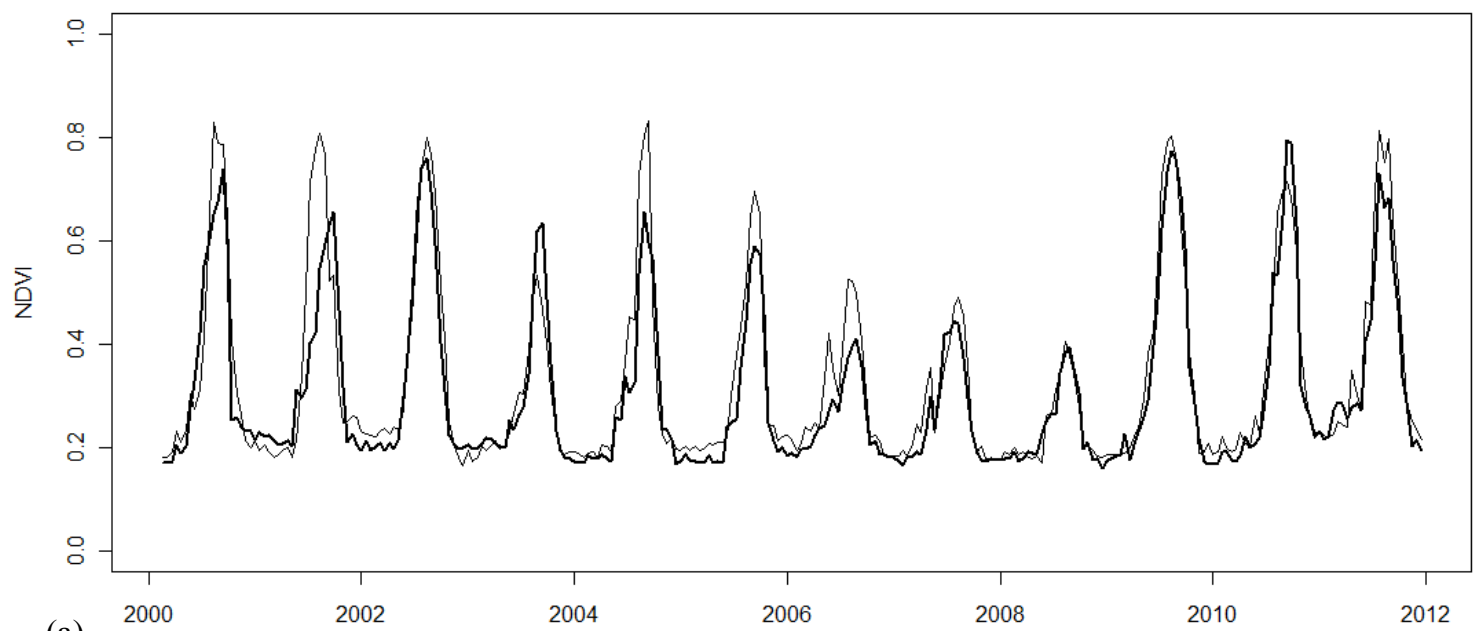

(a)

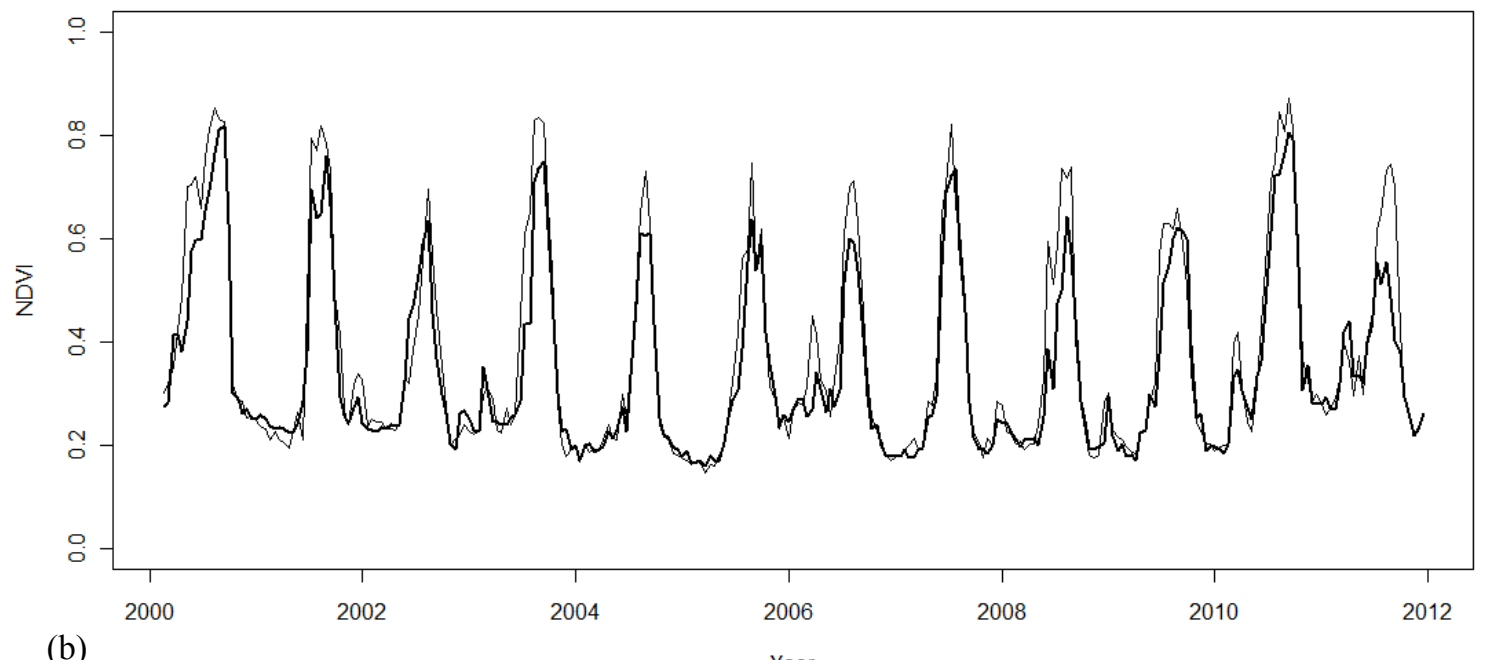

(b)

Figure 2 Time series of NDVI at (a) Minnipa and (b) Wharminda. The darker lines show NDVI of pixels with high PAWC.

\subsection{Relationship between Phenologic metrics and rainfall amount and seasonality}

The rainfall seasonality interacting with PAWC reflects differences in the vegetation growth. This is exemplified for Wharminda in Figure 3. The illustration compares 16 days cumulative rainfall variability with the difference of the rate of vegetation growth between the two representing pixels. Reflecting rainfall seasonality and amount, NDVI around the soil points showed substantial variability. On both paddocks, locations with lower PAWC (Pixel 395 of Wharminda and Pixel 353 of Minnipa) show a faster increase of NDVI compared to locations with higher PAWC.

NDVI of Pixel 395 generally peaks earlier than that of Pixel 394 (Figure 3). In some years (e.g. 2006 and 2007), the rainfall was more dominant in the earlier seasons. Early rainfall filled the soil profile to support the 
vegetation growth during the low rainfall season. The greater water holding capacity of the sandy soil supports faster plant growth than the loam over clay soil.
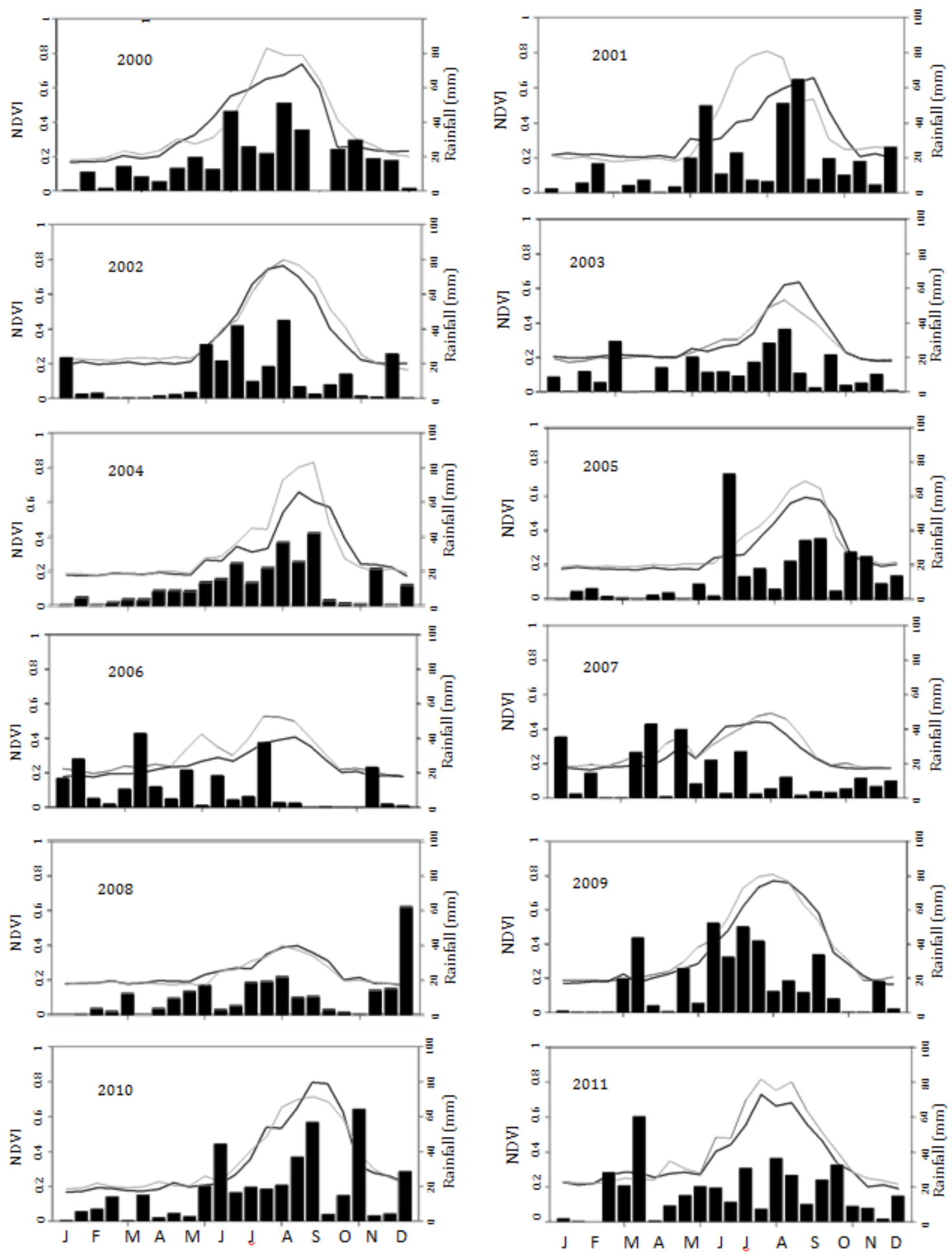

Figure 3 Time series of NDVI and rainfall at Wharminda. The darker lines show NDVI of pixels with high PAWC.

In the year 2006, rainfall was dominated towards the warmest summer seasons, which may be lost through evaporation due to the high temperature during the summer season. The April-May rainfall was low, following the fair rainfall in the beginning of May. The NDVI of Pixel 395 sets to onsets before the vegetation at Pixel 394. The year 2007 was also with very low rainfall throughout the growing season. The vegetation in both soil type reached to Onset at a similar time, followed by steep NDVI increment in the loam 
soil as a result of low June and July rainfall. The years 2008 and 2009 were characterized with lower early rainfall in April and May, results early onset and maximum greenness for the vegetation from Loam soil (Figure 3).

\section{DISCUSSION AND CONCLUSIONS}

The PAWC is a controlling factor for vegetation growth in dryland agriculture, especially in arid and semiarid farming area like South Australia and determines phenological events. Understanding how growth variability is affected by rainfall seasonality and soil PAWC interactions may allow us to work towards inverse modeling schemes that infer about soil conditions based on the spatio-temporal differences in satellite imagery. Growth dynamics can be quantified as variability of the phenological stages including the time of maximum NDVI (MaxT), time of Onset (OnsetT) and combined effect on the rate of growth (GURate).

The GURate was observed to be higher in low PAWC corresponding with an earlier onset and higher maximum NDVI than the relatively higher PAWC soils. This corresponds with observations by Robertson et al., (1994) who studied wheat crop under water deficit during early, mid and late phenologic periods and found that the timing of heading phenologic stage is highly affected by the water deficit. The stressed crop (Robertson et al., 1994) reached heading and anthesis stages approximately 5 and 3 days earlier than the nonstressed crops. Moreover, the study showed that the early stress had the largest effect on developmental timing comparing to the mid and late stresses (Robertson et al., 1994). Numbers of similar experimental research works have been done to assess the effect of inadequate water availability, at various growth stages, on the growth of different crops. These research projects indicate that the timing of growth stages and duration are highly influenced by water availability. Faster crop growth rate is one of the evident effects of water stress during crop growth (McMaster et al., 2003, McMASTER, 2005, McMaster et al., 2011).

The low PAWC soils in both paddocks meant that these soils stored less water and at the time of water scarcity, the soil with higher storage capacity could sustain plant growth compared to low PAWC soils. Thus the vegetation on low PAWC soil faces water stress earlier than the high PAWC soils, which cause the vegetation to accelerate growth to the next growth stages. This can be seen a fast raising curve in the NDVI time series curve, which is measured as GURate for the lower PAWC soils.

Comparing the differences in the growth stages, the maximum is observed at the time maximum NDVI (MaxT). These agreed with the observation made by previous researchers (Angus et al., 1977, Robertson et al., 1994, McMaster et al., 2003, Brisson et al., 2005, McMaster et al., 2008) on the fact that the water deficit affected the anthesis phenological stage, which could loosely correspond to the maximum NDVI (MaxV and MaxT), is more than the other stages. At Wharminda we also observe a higher nutrient concentration in the shallow loam, producing a higher establishment rate and higher initial biomass without yield improvement (Eyre Peninsula Farming Systems, 2009). Potential improvements in inverse modeling of yield may come from focusing on the later part of the season to distinguish bucket size from other growth factors that influence leaf area development. NDVI during the earlier part of the season may be more strongly influenced by moisture content and nutrient concentrations in the upper soil layers rather than the total available water.

There appears to be a strong soil-related signal in the NDVI dynamics. However, the complexity of soilrainfall interactions may require a very large sample size to allow for an automated extraction of site conditions from the time series of NDVI for empirical models. Furthermore, there is substantial variability within a MODIS pixel that is averaged out in the NDVI time series and higher resolution imagery may be useful to assess this spatial variability. Another factor that needs to be considered is the scale issue of having a single soil sample that may or may not be representative (Ostendorf, 2011).

The results presented here allow suggestion for the structure of future PAWC models based on NDVI dynamics. Inverse models of PAWC from NDVI should include the rate of greening and the relative timing of the peak NDVI with a stronger consideration of the later part of the season. Whilst there is potential, validation using larger sets of soil core data needs to carefully evaluate if the soil samples are truly representative of a paddock area at the size of the MODIS pixel. Though, this technique can potentially used to zone paddocks based on the MODIS NDVI time series growth pattern.

\section{ACKNOWLEDGMENTS}

The research would have been impossible without the support for scientific research at Minnipa agricultural center. We extend our gratitude to Cathy Paterson for providing detailed information on the previous research. 
Araya et al., Crop phenology based on MODIS NDVI as an indicator of plant available water content

\section{REFERENCES}

Angus, J. and M. Moncur. 1977. Water stress and phenology in wheat. Australian Journal of Agricultural Research 28:177-181.

Asseng, S., J. T. Ritchie, A. J. M. Smucker, and M. J. Robertson. 1998. Root growth and water uptake during water deficit and recovering in wheat. Plant and Soil 201:265-273.

Brisson, N. and M. L. Casals. 2005. Leaf dynamics and crop water status throughout the growing cycle of durum wheat crops grown in two contrasted water budget conditions. Agronomy for Sustainable Development 25:151-158.

DeFries, R., M. Hansen, and J. Townshend. 1995. Global discrimination of land cover types from metrics derived from AVHRR pathfinder data. Remote Sensing of Environment 54:209-222.

Eyre Peninsula Agricultural Research Foundation, E., 2011, Eyre Peninsula Agricultural Research Foundation, Available online at http://www.minnipaagriculturalcentre.com.au/publication-list.html, Accessed at [Jan 14, 2013, 2013]

Eyre Peninsula Farming Systems. 2009. Eyre Peninsula Farming Systems 2009 Summary

FAO, IIASA, ISRIC, ISSCAS, and JRC. 2009. Harmonized World Soil Database (version1.1). FAO, Rome, Italy and IIASA, Laxenburg, Austria.

Henderson, B. L., E. N. Bui, C. J. Moran, and D. A. P. Simon. 2005. Australia-wide predictions of soil properties using decision trees. Geoderma 124:383-398.

Hill, M. J. and G. E. Donald. 2003. Estimating spatio-temporal patterns of agricultural productivity in fragmented landscapes using AVHRR NDVI time series. Remote Sensing of Environment 84:367-384.

Jiang, P., N. R. Kitchen, S. H. Anderson, E. J. Sadler, and K. A. Sudduth. 2008. Estimating Plant-Available Water Using the Simple Inverse Yield Model for Claypan Landscapes.

Kouadio, L., G. Duveiller, B. Djaby, M. El Jarroudi, P. Defourny, and B. Tychon. 2012. Estimating regional wheat yield from the shape of decreasing curves of green area index temporal profiles retrieved from MODIS data. International Journal of Applied Earth Observation and Geoinformation 18:111-118.

Lloyd, D. 1990. A phenological classification of terrestrial vegetation cover using shortwave vegetation index imagery. Remote Sensing 11:2269-2279.

McDonald, G. K. 2006. Effects of soil properties on variation in growth, grain yield and nutrient concentration of wheat and barley. Australian Journal of Experimental Agriculture 46:93-106.

McMaster, G. and W. Wilhelm. 2003. Phenological responses of wheat and barley to water and temperature: improving simulation models. The Journal of Agricultural Science 141:129-147.

McMASTER, G. S. 2005. Phytomers, phyllochrons, phenology and temperate cereal development. The Journal of Agricultural Science 143:137-150.

McMaster, G. S. and J. C. Ascough, II. 2011. Crop management to cope with global change: a systems perspective aided by information technologies. Pages 172-190 CABI Climate Change Series, Volume 2. CABI, Wallingford.

McMaster, G. S., J. W. White, A. Weiss, P. S. Baenziger, W. Wilhelm, J. Porter, and P. D. Jamieson. 2008. Simulating crop phenological responses to water deficits. Response of crops to limited water: understanding and modeling water stress effects on plant growth processes 1:277.

Morgan, C., J. Norman, R. Wolkowski, B. Lowery, G. Morgan, R. Schuler, P. Robert, R. Rust, and W. Larson. 2000. Two approaches to mapping plant available water: EM-38 measurements and inverse yield modeling. Pages 113. American Society of Agronomy.

Mullins, J. 1981. Estimation of the plant available water capacity of a soil profile. Soil Research 19:197-207.

Oliver, Y., M. Wong, R. Robertson, and K. Wittwer. 2006. PAWC determines spatial variability in grain yield and nitrogen requirement by interacting with rainfall on northern WA sandplain. Pages 10-14.

Ostendorf, B. 2011. Overview: Spatial information and indicators for sustainable management of natural resources. Ecological Indicators 11:97-102.

Reed, B. C., J. F. Brown, D. VanderZee, T. R. Loveland, J. W. Merchant, and D. O. Ohlen. 1994. Measuring Phenological Variability from Satellite Imagery. Journal of Vegetation Science 5:703-714.

Robertson, M. and F. Giunta. 1994. Responses of spring wheat exposed to pre-anthesis water stress. Australian Journal of Agricultural Research 45:19-35.

Rodrigues, A., A. R. S. Marcal, and M. Cunha. 2011. PhenoSat : A tool for vegetation temporal analysis from satellite image data. Pages 45-48 in Analysis of Multi-temporal Remote Sensing Images (Multi-Temp), 2011 6th International Workshop on the.

Solano, R., K. Didan, A. Jacobson, and A. Huete. 2010. MODIS Vegetation Index User's Guide (MOD13 Series).

Sun, H., A. Xu, H. Lin, L. Zhang, and Y. Mei. 2012. Winter wheat mapping using temporal signatures of MODIS vegetation index data. International Journal of Remote Sensing 33:5026-5042.

Wardlow, B. D. and S. L. Egbert. 2008. Large-area crop mapping using time-series MODIS $250 \mathrm{~m}$ NDVI data: An assessment for the U.S. Central Great Plains. Remote Sensing of Environment 112:1096-1116.

Wardlow, B. D., S. L. Egbert, and J. H. Kastens. 2007. Analysis of time-series MODIS $250 \mathrm{~m}$ vegetation index data for crop classification in the U.S. Central Great Plains. Remote Sensing of Environment 108:290-310.

Wong, M. and S. Asseng. 2006a. Determining the Causes of Spatial and Temporal Variability of Wheat Yields at Subfield Scale Using a New Method of Upscaling a Crop Model. Plant and Soil 283:203-215.

Wong, M., Y. Oliver, M. Robertson, and K. Wittwer. 2006b. Technologies to estimate plant available soil water storage capacities at high spatial resolution. Pages 10-14 in 13th Australian Agronomy Conference, Perth, West Australia.

Zhang, X., M. A. Friedl, C. B. Schaaf, A. H. Strahler, J. C. F. Hodges, F. Gao, B. C. Reed, and A. Huete. 2003. Monitoring vegetation phenology using MODIS. Remote Sensing of Environment 84:471-475. 